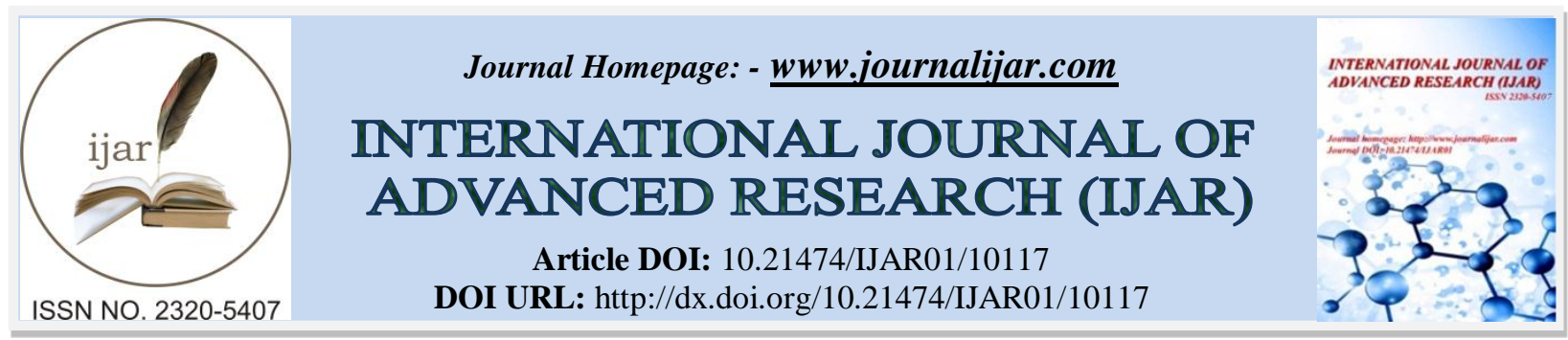

RESEARCH ARTICLE

\title{
INTEREST AND PRINCIPLES OF ENDODONTIC DISINFECTION: CASE REPORT.
}

\section{DakkakI Jalila ${ }^{1}$, Dhoum Sara ${ }^{1}$, Dr. Drouri Sofia ${ }^{1}$, Dr. Skalli Radia ${ }^{2}$ and Jabri Mouna ${ }^{3}$.}

1. Assistant professor, department of restorative dentistry and endodontics, school of dentistry of Casablanca; Morocco.

2. Resident, department of restorative dentistry and endodontics, school of dentistry of Casablanca; Morocco.

3. Professor, department of restorative dentistry and endodontics, school of dentistry of Casablanca; Morocco.

\section{Manuscript Info}

Manuscript History

Received: 01 October 2019

Final Accepted: 03 November 2019

Published: December 2019

\section{Abstract}

The main objective of any root canal treatment of an infected teeth is to eliminate microorganisms that colonize the canal system. This disinfection is essentially based on a chemo-mechanical preparation, the endodontic instruments to shape the main canal, associated to the action of the irrigation solutions.

The irrigation sequence should begin as soon as the access cavity is performed, during root canal shaping and at the end of the root canal preparation, in order to remove the smear layer generated by the action of the shaping instruments. This action is obtained by the combination of $2.5 \%$ sodium hypochlorite and an EDTA-based chelator (Ethylene diamine tetracetic acid).

We will explore this whole process through a clinical case with cystlike chronical periapical periodontitis.

Copy Right, IJAR, 2019,. All rights reserved.

\section{Introduction:-}

In daily practice, each operator is confronted with the treatment of necrotic teeth with or without apical periodontitis. They represent a major public health problem and are underestimated in many countries (1). Indeed, many studies highlight their very high prevalence (1). These lesions are induced by bacteria and their by-products. This was clearly demonstrated by Miller more than a century ago. Undeniably, the necrotic pulp is an excellent substrate for the development of microorganisms. Most of the time, these bacteria remain confined within the endodontic space, while the degradation products can easily pass beyond the apical constriction (2). Thus, the main purpose of treating the infected tooth is to control and eradicate the infection. The means currently available are mainly represented by endodontic irrigation and antiseptic medication whose effectiveness is increased by good root canal shaping (3).

\section{Clinical case :}

1. A male patient represents to the clinic with paroxysmal pain at the upper maxillary area.

2. The medical examination revealed a history of dental traumatism.

3. Clinical examination reveals two composite restorations at 21 and 11 .

4. The sensitivity tests were negative at the 11,21 , and 22 . The axial percussion is slightly painful on \#22.

5. The radiographic examination shows : (Fig 1)

6. A radiolucent image regarding \#11.

7. An incomplete endodontic treatment at \#21. The patient reports having done the endodontic treatment at a dentist without any placement of a rubber dam. 
8. A radiolucent cystic-like bone lesion regarding \#22.

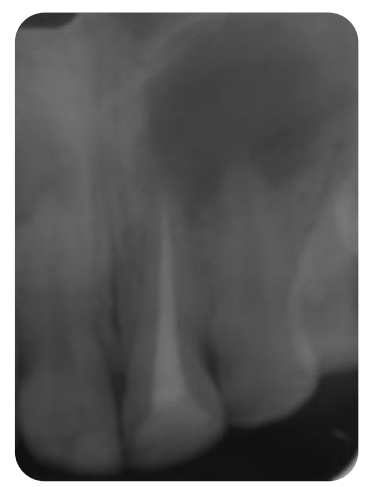

Figure 1:-Pré-operative radiograph showing an incomplete RCT on \#21 with periapical radioluscency regarding \#22 \& \#11.

\section{The diagnosis}

1. Pulp necrosis of the 11 and 22 associated with chronic apical periodontitis.

2. incomplete root canal treatment on the 21 .

\section{Therapeutic decision}

A root canal treatment was decided for the 11 and 22 ensuring the most complete and optimal disinfection possible. After setting up a sealed rubber dam and perform an optimal access cavity, a root canal shaping associated to an irrigation using $2.5 \%$ sodium hypochlorite and final irrigation with a glyde chelating solution was realized.

The root canal filling was realized in the same session as long as the root canals do not show any swelling, pain or bad smell.

the endodontic treatment shows a lack of obturation at the last apical millimeter on the \#21, and it was performed without any rubber dam as reported by the patient. As a result, it was decided to renew the endodontic treatment as a safety measure.

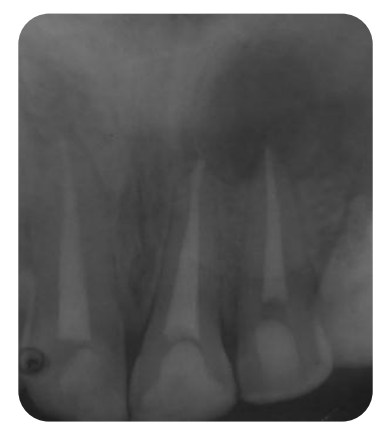

Figure 2:-Prot operative retro-alveolar radiograph showing the RCT on \#11, \#21 \& \#22.

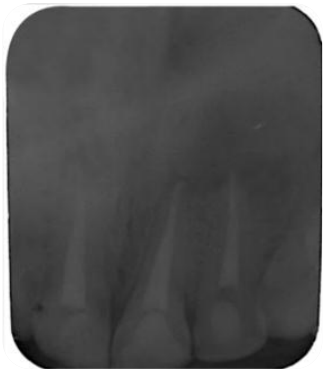

Fig 3:- Beginning of regression of the periapical image after two months of the treatment. 


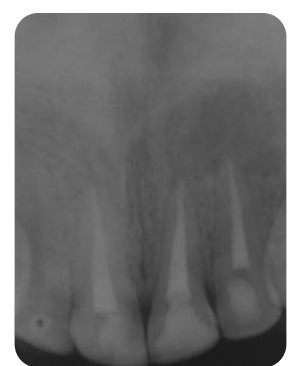

Fig 4:- Beginning of regression of the periapical image after four months of the treatment.

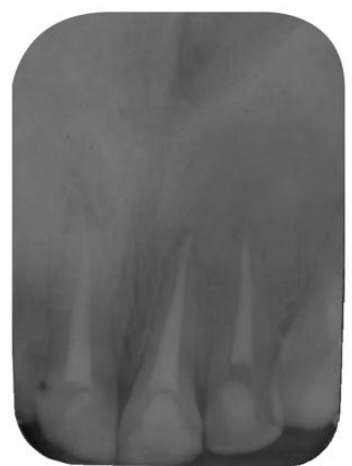

Fig 5:- Regression of the periapical image after four months of treatment at 11 and bone apposition regarding \#22.

\section{Discussion:-}

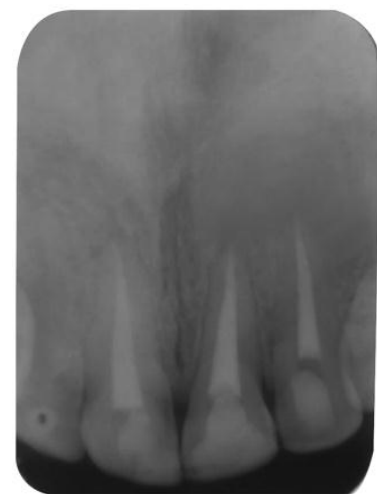

Fig 6:- Disappearance of the lesion regarding \# 22.

A better knowledge of microorganisms and their mechanism of action is essential and allows on the one hand to clearly identify the germs involved and on the other hand to guide research on the bactericidal action of irrigation solutions . Recently, Siqueira and Rocas published a literature review listing all the studies that identified persistent microorganisms after endodontic disinfection procedures (4).

It is possible to highlight the presence of an essentially anaerobic bacterial flora whose composition varies according to the form of the periapical pathology and the time of the infection appearance. These bacteria are organized in biofilms with intercellular matrix. This organization gives the endodontic flora resistance to antibacterial substances (4). Topographically, bacterial biofilms can be classified as :

1. Intracanal biofilms

2. Extraradicular biofilms

3. Periapical biofilms

4. Biomaterial-centered infections.

The germs responsible are mainly bacteria belonging to Actinomyces, Enterococcus and Propionibacterium species. Studies about the action of irrigation agents on these bacterial biofilms revealed that they were very difficult to remove because of their nature on the one hand and their location on the other hand $(5,6)$. Indeed, biofilms are 
mainly found at the apical area, where disinfection is the least effective. The resistance of biofilms to antiseptic solutions can be attributed to different mechanisms. The dense structure and organization of biofilms would prevent the penetration of antibacterial agents and leave intact the deepest microorganisms. These agents could be inactivated within the biofilm itself. In addition, bacteria organized in biofilms may have distinct phenotypes much more resistant to antibacterial solutions $(7,8)$. At present, only sodium hypochlorite would be able to disrupt this bacterial aggregate.

In addition, the plugging of the dentinal tubules by the smear-layer prevents the irrigants from acting in these crevices, it results in bacterial persistence within the canal system that may be responsible of the failure of the endodontic treatment (9). In addition, this layer can significantly close some accessory or lateral canals, thus preventing optimal disinfection of the canal system. This barrier is not hermetic and appears non-homogeneous under microscope. It prevents the adhesion of root canal cements as well as intra-canal medications.

Because of its composition both organic and mineral, a single irrigation solution is not sufficient to completely eliminate the smear-layer. The most commonly used solutions include different concentrations of sodium hypochlorite and EDTA (10).

These findings lead us to respect the biological foundations in order to be part of the most reliable therapeutic approach possible. These basic endodontic rules are perfectly codified by the literature and include $(11,12)$ :

1. Preparation of the tooth for treatment : Removal of caries and pre-endodontic restoration.

2. Canal shaping through instrumentation (optimal taper);

3. Irrigation with an antiseptic and solvent solution.

4. Obturation of the endodontic system when optimal conditions are obtained.

5. Clinical and radiographic follow-up of the treatment over the time.

\section{The rubber dam}

The use of the rubber dam is an essential. It has many advantages, especially the hermetic isolation of the concerned tooth from the septic oral environment. It avoids salivary contamination and reinforces endodontic irrigation while maintaining asepsis of the canal system during shaping.

The pre-endodontic reconstitution by using a metal matrix and a glass ionomer cement or by using a ring permit to restore a coronary morphology compatible with the stability of the clamp and thus the sealing of the operating field. It also makes it possible to obtain a four-walled access cavity which will serve as a pool for irrigation solutions, as well as the coronary temporary restoration (11).

\section{Root canal shaping}

Endodontic preparation is conceived as a chemo-mechanical preparation where the instrumental shaping influence the quality of endodontic disinfection. The most important thing is to obtain a regular and sufficient taper while respecting the initial trajectory of the main canal. This conicity, brings irrigation solutions along the canal and in large quantities, is currently obtained using the Crown-Down technique.

Many authors have studied the principle of shaping the apical third in order to eliminate as many bacteria as possible, and it is clear from their studies that it is necessary to maintain the foraminal diameter, to avoid the propulsion of the debris in the periapical area and to ensure the sealing of canal fillings to guaranty the apical healing. Respect of the working length is also a key factor of endodontic success $(11,12)$.

The use of Ni-Ti instruments overcome to the rigidity of stainless steel instruments and to bypass anatomical obstacles. These instruments have improved through the years to enhance profiles and have a better debris clearance. However, in the literature, there is no difference between manual and rotary instrumentation if the irrigation is well conducted. Indeed, all the studies emphasize that the operative technique remains the most important way to achieve the biological healing goals $(11,13)$. Consequently, for all the systems the most important thing is to respect the operating sequence by using the recapitulation files and permeability, to have a sufficient taper necessary for the renewal of the irrigation solution. 


\section{Endodontic disinfection}

The current state of knowledge favors endodontic treatment in "one sitting". Indeed, the first Scandinavian studies recommended the use of calcium hydroxide in the case of infected teeth $(14,15)$. This concept was based on obtaining an increased apical diameter with a distance of $1 \mathrm{~mm}$ from the foramen to not damage this area. Thus, it remains a non-instrumented portion, explaining the importance of using a medication for several weeks to complete the disinfection. These studies are from twenty years and are based on bacterial cultures where all strains cannot be detected $(14,15)$.

In addition, current studies based on molecular biology have compared the effectiveness of calcium hydroxide with sodium hypochlorite. It appears that the results would be the same $(14,15)$. Consider for example the randomized study of Waltimo that compares the success rate at 12 months of treated teeth in one or more sessions and highlights that the establishment of calcium hydroxide in inter-session is not followed by a better success rate (16). In addition, other authors have shown that calcium hydroxide is not effective on Enterococcus Faecalis and that its $\mathrm{pH}$ is quickly neutralized by acidic bacterial products and by phosphates of dentin hydroxyapatite which limit diffusion. $\mathrm{H}+$ and $\mathrm{OH}-$ ions.

In addition, the three-dimensional filling with a cement and heated gutta prevent developing of the residual bacteria. According to Fuss et al., The release of eugenol from eugenol zinc oxide-based cements gives them a bactericidal power (17).

As a result, irrigation will play a very important and essential role in the aseptic-antiseptic chain because, whatever the system used, it is impossible to instrument all the rootwalls. It has been shown that only $55 \%$ to $70 \%$ of the walls of a correctly shaped canals are concerned by the mechanical instrumentation (9). As a result, irrigation supplements the mechanical preparation by a physical action of channel lubrication, suspension of canal debris and a chemical action by dissolving the organic and mineral materials while neutralizing microorganisms and their derivatives.

Nowadays, none of the products on the market can fill all the qualities required of the ideal irrigation solution. Thus, the combination of several solutions is required to achieve as complete as possible the cleaning and disinfection. Sodium hypochlorite is still the reference irrigant in endodontics. It has a dissolving action on necrotic tissues and antiseptic power widely demonstrated. However, on its own, it has no power over the mineral content and must be completed by a demineralizer.

The recommended concentrations vary between $0.5 \%$ and $5.25 \%$. These concentrations are obtained from the dilutions of the base solution or by the use of the stabilized ones. However, the concentration of $2.5 \%$ seems to be the best compromise between efficiency and absence of toxicity. Its effectiveness also depends on the volume of the solution and its renewal to the extent that the available chlorine must always remain in excess of the amount of material to dissolve $(18,19)$.

Moreover, Cunningham has shown that raising the temperature to $37^{\circ} \mathrm{C}$ of the $2.5 \%$ sodium hypochlorite solution potentiates its solvent power and its efficiency becomes comparable to that of a $5.25 \%$ solution (19).

Demineralizers remain useful as the chelating gel can lubricate the channel, an easier use of Ni-Ti instruments and negotiating fine or difficult canals by softening the dentin slightly. At the end of the preparation, rinsing the canal with a liquid chelator such as EDTA (ethylene diamine tetracetic acid) at 17\% eliminates the smear layer.

Thus, the combination of sodium hypochlorite and EDTA is the most effective irrigation sequence for perfect disinfection. Clinically, the operative sequence should be three-dimensional irrigation. It is therefore advisable to have an initial irrigation as soon as the access cavity is opened, to continue throughout the canal shaping and a final irrigation in order to eliminate all the smear layer material (20).

The disintegration of the bacterial biofilm in the non-instrumented zones can only be done by the activation of the solution inside the canal network at the end of the canal preparation, which justifies the use of the files associated with ultrasonic tips at the end of the shaping (21). This activation generates a process of cavitation causing an increase in the temperature of the irrigation solution, which potentiates its properties. According to Pierre Machtou, the circulation of irrigation solutions is limited in the apical third and only the agitation of the solution to the working length allows its complete renewal. This activation can be done simply using a gutta cone animated by a vertical pumping movement of 4 to $5 \mathrm{~mm}$ amplitude for 1 or 2 minutes (11). 
Recommendations for an ideal disinfection of infected teeth :

1. A sealed operating field and access cavity with four walls.

2. Initial irrigation with $2.5 \%$ sodium hypochlorite once the access cavity is performed.

3. irrigation with of $0.5 \mathrm{ml}$ of sodium hypochlorite after each file passage.

4. file coating with chelating gel before it is introduced into the channel.

5. Final irrigation once root canal shaping is complete:

6. Irrigation with $1 \mathrm{ml}$ of liquid EDTA for 2 minutes, activated with ultrasound to remove the smear layer.

7. Final irrigation with sodium hypochlorite followed by activation.

8. If the endodontic filling cannot be completed in the same session (swelling, pain, complicated endodontic anatomy), temporary filling with calcium hydroxide performed to protect the endodontic system from a secondary contaminations.

\section{Conclusion:-}

Respect of antisepsis is one of the major goals of endodontic treatment. This implies a rigorous treatment methodology that respects all the operating steps, ranging from a sealed surgical field and a chemo-mechanical preparation as effective as possible until the establishment of an antiseptic medication following the indications.

Finally, a root canal filling and tight coronal reconstitution seal the endodontic system and thus maintain the result obtained. Advances in technology have allowed therapeutic approaches to focus on endodontic treatment in one session increasing the success rate of the endodontic therapy.

\section{References:-}

1. Y. BOUCHER. Parodontites apicales et mauvais traitements endodontiques : état d'urgence. Rev Odont Stomat $2005 ; 34: 205-217$.

2. H. SCHILDER. Cleaning and shaping the root canal. Dent Clin North Am 1974; 18: 269-296.

3. G. CANTATORE. Struttura dentinale e procedure endodontiche. Dent Cadmos 1995; $2: 13-45$.

4. J. SIQUEIRA, I. RÔÇAS, A. FAVIERI, KC. LIMA. Chemomechanical reduction of the bacterial population in the root canal after instrumentation and irrigation with $1 \%, 2,5 \%$ and 5,25\% sodium hypochlorite. J Endod. 2000; $26: 331-334$.

5. G. CANTATORE. L'irrigation de l'endodonte : importance dans le nettoyage et la stérilisation du réseau canalaire. . Réalités cliniques 2001 . Vol. 12 , n² :185-201.

6. F. BUKIET, C. ROLLAND, N. GARDON, L. POMMEL. Optimiser l'antisepsie canalaire par une irrigation efficace. Réalités cliniques 2006. Vol. 17, nº :371-383.

7. Gilbert P, Das J and Foley I, Biofilm susceptibility to antimicrobials. Adv. Dent. Res., 1997: 11, 1, 160-7.

8. Stewart P S and Costerton J W, Antibiotic resistance of bacteria in biofilms. Lancet, 2001: 358, 9276, 135-8.

9. C. MADER, J.C. BAUMGARTNER, D. PETERS. Scanning electron microscopic investigation of the smeared layer on root canal walls. J Endod $10: 477-483,1984$.

10. O'Connell MS, Morgan LA, Beeler WJ, Baumgartner JC. A comparative study of smear layer removal using different salts of EDTA. J. Endod, 2002 Dec; 26 (12): 739-43.

11. P. MACHTOU. Deux décennies d'endodontie. Réalités cliniques 2010. Vol. 21, nº1:41-51.

12. JM. LAROUSSE, GM. GIMENEZ, JP. ROCCA, P. GUERRI. Pharmacologie endodontique, evolution des concepts. Réalités cliniques 1992. Vol. 3, nº 1 :131-137.

13. I. COCHET. Quelles règles doit-on respecter lors de la préparation canalaire apicale ? Inf.dent, n³7, Oct 2004 : 2427-2430.

14. V. DESCROIX, F. BRONNEC, WILHELM-J. PERTOT, F. RILLIARD, K. YASUKAWA, P. ROCHER, M. GOLDBERG, S. KLEINFINGER. Médicaments et dispositifs médicaux en endodontie. Cahier de l'ADF, 2008.

15. JM. LAROUSSE, GM. GIMENEZ, JP. ROCCA, P. GUERRI. Pharmacologie endodontique, evolution des concepts. Réalités cliniques 1992. Vol. 3, n¹ :131-137.

16. WALTIMO T, TROPE M, HAAPASALO M, ØRSTAVIK D. Clinical efficacy of treatment procedures in endodontic infection control and one year follow-up of periapical healing. J Endod. 2005 Dec;31(12):863-6.

17. FUSS Z, WEISS EI, SHALHAV M. Antibacterial activity of calcium hydroxide-containing endodontic sealers on Enterococcus faecalis in vitro. Int Endod J. 1997 Nov;30(6):397-402.

18. Baumgartner JC, Cuenin PR. Efficacy of several concentrations of sodium hypochlorite for root canal irrigating. J.Endod 1992 Dec; 18 (12): 605-12.

19. CUNNINGHAM WT, JOSEPH SW. Effect of temperature on the bactericidal action of sodium hypochlorite endodontic irrigant. Oral Surg Oral Med Oral Pathol. 1980, Dec;50(6):569-71. 
20. G. CARON, K. NHAM, F. BRONNEC, P. MACHTOU. Effectiveness of different final irrigant activation protocols on smear layer removal in curved canals. J Endod. 2010; 36: 1361-1366.

21. Mozo S. Liena C. Forner L. Review of ultrasonic irrigation in endodontics: increasing action of irrigating solutions. Med Oral Patol Oral Cir Bucal.2011, Dec 6. 